\title{
Three Academic Problems on Music Iconography in China: Direction, Position, and Path
}

\author{
LIU Yu-tong \\ Yibin University, Yibin, China
}

\begin{abstract}
As an emerging discipline which interrelates with musicology and iconology, the Music Iconography in China is still at the beginning stage. In the past 30 years, its research methods have been the focus of debate in regard to its academic direction, academic position, and academic path. These three "academic problems" should be paid attention because they not only sustain our current research and construction of Music Iconography's future and destiny, but also become major theoretical and practical issues. The author advocates that the academic direction should maintain highly consistent with the reality of China, as well as the academic practice. In order to guarantee the academic direction and academic position, we should adopt the academic path from these two aspects: "the horizontal logic" and "the longitudinal logic”.
\end{abstract}

Keywords: Music Iconography, academic orientation, academic position, academic path

\section{Introduction}

The research and construction of modern Music Iconography have special rules and requirements since they are uniquely positioned in the comprehensive construction of musicology system. With the increasing prosperity of academic activities in the last three decades, Music Iconography is now in a remarkable development stage, despite of its difficult experience as a "hidden subject" in the past. It is not completely accurate to judge it "active and strong, but in an disorder and intangible state” (LUO, 2009, pp. 66-70), however it is urgently required to accurately understand the academic direction and academic position, and also clarify its academic path. These three "academic problems" should be paid attention because they not only sustain our current research and construction of Music Iconography's future and destiny, but also become major theoretical and practical issues.

\section{Adhering to the Academic Direction of “Consistent with China's Reality”}

The research and construction of Music Iconography in China can be roughly divided into interdependent, correlative, and complementary aspects, i.e.: practice, theory, and discipline system of Music Iconography. Among them, the research and construction of the theory serve as a foundation and also a "superstructure" that restrict and influence the overall level and quality of Music Iconography's research and construction. Thus it is vital to clarify the academic direction based on the methodological principle of historical materialism.

LIU Yu-tong, master, associate professor, Theory Research Department, College of Music and Performing Arts, Yibin University. 
From the perspective of historical materialism, every kind of theory must withstand the test of practice. Communist Party of China (C.P.C) has put forward the program and strategic mission of building a modern socialist country with Chinese characteristics: So we should stick to the fundamental principle of Marxism to follow the socialist road; on the other hand, we should take our own development path according to the reality of China, which could be regarded as a reference and guidance in the research and construction activities of Music Iconography in China. Just like the basic principle of Marxism, the Music Iconography theory is an advanced theory borrowed abroad, which plays different roles in different fields and disciplines. We must carry forward its merits, but also abandon its disadvantages unsuitable for the reality in China. Therefore, it is essential that, with regard to the development direction, the research, and construction of Music Iconography must reflect the objective demands of China's modernization drive, and keep consistent with the reality of China, so as to leverage and guide the practice in every aspect of Music Iconography.

For over two decades, some intelligent scholars were devoted to the research and innovation of Music Iconography theory, and some new achievements were made to meet the reality and demand of development in China. Also, as individuals, they have grown into well-known scholars in research and construction of Music Iconography, realizing their value of lives. In "Musical Iconology: Its History, Current Situation, and a Modest Proposal for Its Future Development, Mr. LI (2006, pp. 94-100, 135) listed some important academic writings from 1981 to 2002, as well as some descriptive articles. However, we must be aware of the tendency inconsistent with the reality of China — canonizing the theoretical pattern put forward by foreign scholars while neglecting the accomplishments made by China in the traditional Music Iconography within nearly 1,000 years, leading to lack of Chinese characteristics and styles. For instance, some scholars stubbornly followed the theory of "three stages or layers" and subsequent "Four Stages" proposed by a German scholar Erwin Pannofsky, taking them as the standard to judge the accomplishments of research and construction of Music Iconography made in China. According to their viewpoints, "there is still an enormous gap between China and Germany in research and methods of Music Iconography” (LUO, 2009, pp. 99-102). Indeed, there’s still a long way for the research and methodology for China's Music Iconography. The current research and construction of Music Iconography in China require to broaden our visual field, and adjust our thought to analyze the issues with relative mature theories, but never regard as the highest standard, or even undermine, obliterate, or replace our traditional research methods. Such practice just following the suit of Westen Music Iconography is obviously inconsistent with "the reality of China".

The well-defined academic direction in research and construction of Music Iconography is crucial to guide correctly the research practice of Music Iconography in China. Western scholars in Music Iconography advocate to "have a deep understanding of the culture in certain era through icons-namely historic properties like politics, religions, academic status and daily lives” (LUO, 2009, pp. 99-102). That is to say, the conclusion drawn by analyzing icons according to Music Iconography could help construct certain ideology to some extent. The fundamental interests of a certain ruling (leading) social class are represented by certain ideology, whilst the conflict and struggle among different classes and social systems are always manifested through ideological difference and contention. The academic practice of Music Iconography started in China in the Northern Song Dynasty or even earlier. The ultimate aim of the research for musical instrument images in related epigraphy was 
to supplement the contents and fill a vacancy in the history of Chinese music. For example, when studying these instrument images, musicians like Shen Kuo, mainly focused on the influence of Acoustic Principles on the structure of chimes, rather than sociological reasoning about the changes of the chime shapes from tile-like to round ones. When analyzing the painting Night Revels of Han Xizai, both QI Gong and LIANG Ji-hai focused on the theme of music in the picture, but not like Peter Zhang, who just analyzed it with the thinking mode of Western Music Iconography, making an odd conclusion that "the purpose of the artist is to make the viewers admire Han's techniques and attainment in literature and music, rather than despise Han's personalities and life style” (WANG, 2005, pp. 4-12). That's because when Chinese scholars appreciated the painting, they previously reached a consensus that no Chinese viewers would regard it as "despising Han's personalities and life style". What foreign scholars considered as a problem was not really a problem of Chinese scholars at all. It is unavoidable that scholars from different cultures and backgrounds have different perspectives, thus a rigid comparison across ideologies to debase each other cannot be conducted. The "ideological differences" will cause misunderstanding on the same object of research, therefore the research and construction of Music Iconography should follow its own path from the reality of China. The former president of the United States Nixon once said, "all our communications in terms of weapons, treaties, trades, foreign aids and cultures will become meaningless if we lose in the battle of ideology field" (WAN, 2007, pp. 150-155). Therefore, it is necessary to communicate with overseas academic circles in the process of research and construction of Chinese Music Iconography, but its academic direction shall be always consistent with the reality of China.

In order to adhere to the direction consistent with the reality of China, we shall firstly put the basic spirit of Chinese traditional academic system into academic practice, reflecting the style and manner of research and construction of contemporary Music Iconography in China. The research tradition over one millennium and the research and construction of contemporary Music Iconography are embraced within the musicology system with Chinese characteristics, and should be incorporated into a broader discipline logically. Such incorporation is a "longitudinal logic" construction process in the same academic direction. Secondly, we should absorb the merits from overseas, and also resist the useless or harmful factors for China, manifesting a proper logical relationship between the reality of China and the world today. The foreign Music Iconography theory was not constructed within a day. Its research has experienced different stages and tendencies from religious themes (original meaning of icon) to all art works and then to visual works. Hence, introduction of foreign theory should be emphasized on different periods and various problems needed to be solved, instead of simple reproduction and imitation. Even for those representative cases, we should also pay attention to meet the needs of "practice" faced by our country. This is an issue of constructing "horizontal logic" across the history and reality depending on China's national conditions. Theoretically, this is a transition process from history to reality, and also from exploration to construction, so requires innovative interpretation in tune with the era. For example, innovative interpretation in line with China's traditional culture shall be conducted through research of our traditional music images like paintings of Han Dynasty, Dunhuang frescoes, ancient music and dance images under the guidance of the Music Iconography theory. This requires those skilled in this field to have an open mind and vision to foster awareness of opportunities, speculative wisdom and ability as well as risk awareness, and also adhere unswervingly to the academic direction from the reality of China. 


\section{Adhering to the Academic Position "Based on Practice"}

There is no doubt that a discipline's theory and construction shall stick to academic innovation activities so as to realize academic achievements unceasingly. However, in China, people pay little attention to the "academic position” in Music Iconography. From academic perspective, academic position problem undoubtedly exists in the research and construction of Music Iconography. It is the inherent requirement of Music Iconography theory and research in China to clarify and adhere to the academic position.

"Position", the word, is easy to remind us of "class position" full of political meaning, but that is not the case for its academic meaning. Position is defined in Cihai (2009) (a well-known Chinese dictionary) as: "It is like the foothold which generally refers to the status when observing things and handling problems and the attitude held herefrom” (p. 5059). On one hand, this explains that position is endowed with an objectivity emphasizing the objective fact from which the person observes things and handles problems on the scene; on the other hand, it explains that position also possesses subjective tendency emphasizing the attitude held herefrom will vary from individuals. That is to say, position is within the scope of understanding and practice combining subjectivity and objectivity, and its essence is the attitude of participants. As for the same thing or problem, different people on the scene hold different positions owing to different attitudes instead of without attitudes. ${ }^{1}$ Researchers shall identify their status, hold appropriate attitudes and adhere to appropriate positions in the academic activities of research and construction of Music Iconography.

When conducting research and construction of Music Iconography in China, although its "foothold" is different from our ideological and political theory research with clear political and class characteristics, there seems to lack of any restricted area for research according to the research objects such as "things" and "problems" faced in the academic activity. However, from the "status" and "attitude" of subject, we can not say that there is no position. The achievements in nearly 30-year research and construction of Music Iconography relate to the integrity of academic position of experts and scholars. For example, those achievements, such as: creating Music Iconography's academic degree programs in higher education talent training system, founding Music Iconography in music theory system and trying to establish Music Iconography discipline in art discipline system and setting it as a secondary discipline, directly relate to the academic positions held by researchers of old generations, who consider the research and construction of Music Iconography as the professional platform to train new talents adapted to socialism modernization drive with Chinese characteristics.

The academic position for research and construction of Music Iconography in China, namely the foothold of academic activities, shall be geared towards practice of Music Iconography. The basic objective and purpose of Music Iconography are to explore the objective laws of practice of Music Iconography and propose new requirements based on practice of Music Iconography; guide and affect the practice of Music Iconography through applicable scientific achievements to improve its whole efficiency; besides, these represent the effective methods and approaches that implement Music Iconography as an independent discipline of musicology. Practice belongs to the basic category of materialism epistemology, which is given top priority in historical materialism's methodological discipline system. "Based on practice" is regarded as the basic position and method for people to know and control the nature, society, and mankinds themselves. Chairman MAO (1990) pointed out in The

\footnotetext{
${ }^{1}$ Without attitude itself refers to an attitude and a position.
} 
Theory of Practice: "only social practice can be the criterion of truth. The viewpoint of practice is the first and fundamental viewpoint of dialectical materialism epistemology" (p. 284). The position "based on practice" refers to the position of "practice first" or "practice priority". Music Iconography is a highly practical discipline whose vitality depends on building inherent logic connections with Music Iconography practice, and practically showing the significance and value in using and guiding Music Iconography practice. It advocates to regard practical work and theoretical research of Music Iconography as the same process but also two different links correlated to each other at the same time.

According to the reality of 30-year research and construction of Music Iconography in China, the problems on three aspects need to be discussed and resolved for adhering to the academic position "based on practice":

(1) Overcoming the disadvantage due to separation of music iconography and music iconography research.

Practically, the separation of Music Iconography and Music Iconography research has existed for a long time, because the former one refers to conscious or spontaneous academic activities by researchers of old generations in music history researches, and the activities in connection with research of images or maps relate to the academic tradition of our valued "map research"; while the latter one refers to the outcome from introduction of Western learning, wherein Music Iconography has formed its inherent research subjects, methods, and purposes. When these two researches are developed in China at the same time, the differences of research subjects (on culture characteristics), research methods and paths (on academic traditions), research purposes and goals (the former aims to complement beneficially Chinese music history and the latter aims to build independent disciplines) will surely result in an embarrassing situation that both of them are separated from each other and will separate for a long time. The academic shortcomings and disadvantages shall give us a warning because these will lead to shift of academic focus, waste of academic power and disunity in academic field. There are lessons that are evidenced by the separation and incompatibility between the development of musicology and ethnomusicology in China and our folk music theoretical research.

The discrete academic pattern has deep impact on those engaged in discipline construction of Music Iconography in colleges and universities. Some of them just prefer to talk about their theoretical thinking and achievements but show no interest in many problems and puzzles in practical work of Music Iconography; and some of them dedicate to exploration of some specific subjects and pay no attention to summarization of general and common theories in similar subjects' researches. It has shown the lack of awareness of "a game of chess” and "overall situation" in academic world, but also represented the ability of integrating such pattern and paradigm in the academic field.

Therefore, if we intend to adhere to the academic position of research and construction of Music Iconography, we should firstly abandon original concepts, transform the discrete pattern and consciously take the practice of Music Iconography as our research subjects and working platforms. Efforts shall also be made to heal the differences between researchers of traditional Music Iconography and theoretical researchers \& builders of Music Iconography, thereby overcoming the disadvantages of separated Music Iconography and Music Iconography, training and enhancing the consciousness and ability that theoretically reflects, utilizes and guides the experimental practice.

(2) Advocating scholarly style facing "academic practice”.

Research and construction of Music Iconography, especially the practice of Music Iconography, represent a 
process of understanding and practice and also a process of solving problems. In the process, it just makes a fuss if the cognition activities of theoretical thinking are not intended to solve problems in practice. For theoretical research —no matter it encounters the issue of ontological significance or empirical significance, if the issue has no connotation in practice, the academic achievements are psuedo-scientific and just reasoned or demonstrated by "taking for granted", regardless of actual situations and needs in practice.

The theoretical research and construction of Music Iconography could have been used to solve the problems occurred in academic practice of modern art and musicology. Thirty-year research and construction of Music Iconography in China witnessed the achievements as a result of resolving such problems in practice; also its further expansion and development cannot be separated from practice. It is necessary for more Music Iconography literatures to learn and develop a useful knowledge theory since work behind closed doors seems undesirable under the new development trend of socialist modernization drive with Chinese characteristics. All scientific researches based on practice shall be aware of "academic practice". The research and construction of Music Iconography developed in China needs to take an academic position "based on practice" and hold a more vivid consciousness of "academic practice".

(3) Establishment of position coordination mechanism.

The characteristics of mental labor determine that individuals are subjects of academic position in academic activities. However, cultivation of consciousness and ability related to academic position is not completely the matter of individuals, therefore, it is necessary to establish a coordination mechanism accordingly. The research and construction of Music Iconography are always in a spontaneous state in China. An integral academic position mainly relies on loose engagements among research centers-tutors-individuals or is consciously developed by individuals themselves. That is why we need the power of system to correct the discrete academic research phenomenon.

First of all, the coordination and security institutions shall be set up under the leadership and coordination of departments in charge of art and musicology. For example, a Music Iconography association shall be established to focus on and control "academic practice" in daily work, and streamline coordination work as their major responsibilities. The rapid growth of Western Music Iconography benefited from Music Image Library (GAO, 1992, pp. 138-144) — a professional institution founded in Switzerland in August 1971 under the proposal of International Music Society, International Music Library Association and International Museum Association to boost Music Iconography research. If our country wants to develop the research and construction of Music Iconography, it is required to find our own authoritative academic institutions and make full advantage of the security functions other than actively participating in the activities of institutions. Next, we shall advocate a study style "based on practice" and create an academic atmosphere "based on practice" via education and training, so as to fight against the unhealthy style of study that is founded subjectively departing from facts of Chinese academic research. Furthermore, we shall create a professional periodical matrix of Music Iconography, integrate relevant medium to publicize and form a fine research style of theoretical research and discipline construction of Music Iconography based on the practice of Music Iconography.

\section{Adhering to the Academic Path of "Considering Two Aspects"}

Academic path refers to the principles and methods to be used in academic activities of scientific research. 
The academic path of research and construction of Music Iconography is to ensure that the academic direction complies with the practice of China and that the academic position shall be based on the Music Iconography practice. It is the key for affecting and restricting academic direction and position.

In the scope of art and musicology discipline, there is little objection as to whether Music Iconography is a discipline. But many people accept this proposition only in the training of postgraduates and academic degree programs regardless of the entire intrinsic logical structure of the discipline. If all of the visual images associated with music are regarded as the research objects of Music Iconography, the research and construction of Music Iconography should be divided into three essential levels: general Music Iconography, Music Iconography research affiliated to cultural history, art history and music history, as well as independent Music Iconography research (including: Music Iconography discipline education and theoretical research about discipline construction in universities and colleges), each of which has its own internal logic structure. To understand and grasp the academic path of research and construction of Music Iconography, we can neither treat the research and construction of Music Iconography (independent disciplines) equally to general Music Iconography, nor treat it as a "latent discipline" affiliated to some disciplines like Chinese music history. Thus, we should conduct analysis, investigation and construction from these two aspects: "horizontal logic" and "longitudinal logic", helping to clarify the academic path accurately:

(1) Academic path from longitudinal logic.

While analyzing and reviewing from longitudinal logic, this requires regarding our Music Iconography history as a continual process so as to grasp the nature of Music Iconography research. The nature of things lies in their fundamental characteristic, reflecting stable internal relations among structural elements and contradictory movements arising here from. The nature of Music Iconography research should reflect the internal relations among elements like research targets, missions, objects, contents, and methods as well as the contradictory movements therein. Therefore, this requires understanding scientifically the research targets, missions, contents, and objects, of which the research targets decide the missions, contents, objects and methods as well as the times attribute of Music Iconography research.

Epigraphy emerging from Northern Song Dynasty is commonly regarded as the origin of Chinese Music Iconography, but its research target is to "revise mistakes of classics and supplement omissions of history". So, its research mission focuses on recording and textual research; its research object is also restricted to unearthed bronze and portrait stones of Han dynasty, etc.. The iconology was limited by the research objectives: "the Greek Orthodox icons, and later expanded to all images” when it just started in foreign countries (HAN, 1988, pp. 50-55). At the beginning of the establishment, the Music Iconography aimed at "analysis of music history" (GAO, 1992, p. 138) or "one aspect of music history research" (TIAN, 1990, pp. 51-53), so its research missions were closely related to research missions of music history, and its contents were limited to four aspects including: "musical instruments history”, "performance history”, “composers' portraits” and "rational and cultural history” (GAO, 1992, p. 138), or divided into "organlogy" "performance methods", "life stories of composers" and “cultural history” (HAN Guo-huang quoted from Brown's statement as saying) (HAN, 1988, p. 52). The research objects also focused on the instrumental images, instrumental performance images and composers' portraits, etc.. However, along with the further research and construction of Music Iconography, its target began to shift into "a specialized subject aimed at identification, description, classification and explanation of the 
contents and forms of various musical images as well as symbols and themes contained therein” (supported by Chinese Encyclopedia Music \& Dances), “a specialized subject lies amongst music history, art history, literary history and general cultural history” (JIN, 1989, pp. 39-42). Contemporary researchers began to review Music Iconography from interdisciplinary perspective and discussed it about subject education (LI, 2005, pp.102-104). In short, despite of imperfect development of Music Iconography in China, the shift and change of its objectives are obvious. Only by grasping the main objective of Music Iconography's research and construction in different periods could we clarify the specific missions and contents of "academic practice”, whilst the change of specific research missions and contents will surely lead to the change in research scope and methods. In this sense, analyzing and reviewing the academic path of Music Iconography from the longitudinal logic are actually a scientific approach to understand the research targets, missions, contents, objects, and methods of Music Iconography, so as to grasp the nature of Music Iconography better.

(2) Academic path from horizontal logic.

Music Iconography is represented by multi-disciplinary integration. Music Iconography practice shows that the common use of multi-disciplinary theory is the basic approach to study this discipline. To adopt the academic path for the research and construction of Music Iconography from the horizontal logic, it is required to grasp the correlation between Music Iconography and other subjects, and also synthetically utilize methodologies from relevant disciplines. In Chinese musicology discipline system, Music Iconography is trying to separate itself from Chinese music history as an independent discipline. The research and construction of Music Iconography require mature theoretical knowledge in musicology and iconology as well as other multi-aspect mature theories in terms of culture, art, philosophy and aesthetics, etc., of which the key is to build Music Iconography theory itself. In this respect, there are some research paradigms overseas from long-term research and practice on the music icons in religious items, art works and sculptures. However, it is obviously inappropriate to instruct and affect our Music Iconography in Han dynasty stone carvings, Dunhuang frescoes and cliff paintings, etc., with these theories, namely, there must be a sinicizing process in spite of some well-developed theories and methods in Musicology, Iconology and Music Iconography overseas; we can not always conduct borrowlism. Therefore, they said synthetically utilizing methodologies from relevant disciplines is not completely equal to the suggestions of “desalinating competition among disciplines" and "advocating multi-disciplinary interaction” (LUO, 2009, pp. 66-70) put forwarded by some scholars.

Given the academic path to research and construction of Music Iconography in our country from horizontal logic, we are firstly required to analyze and review comprehensively the Music Iconography theory and the logical relation between musicology and its subordinated discipline-Chinese music history. As an independent discipline viewed from the Musicology theory system, Music Iconography should "take its own way" in its theoretical research and construction, and establish a unique theoretical system and presentation pattern to show its discipline characteristics.

But this does not mean that we could conduct the research and construction of Music Iconography beyond the overall perspective, ignore the logical relevance with other parallel disciplines and follow a path to "unilinear development”, "vacuum operation” or unilaterally "geared to international criterion”. We should realize that its theoretical achievements and core value in theory and practice are an integral part of Musicology system, and that 
these kinds of development are an innovation and development based on music history, Music Archaeology and other relevant disciplines with reference to Musicology's core value.

Secondly, to adopt the academic path for the research and construction of Music Iconography from horizontal logic, it requires to analyze and review the logic relationship with other relevant disciplines' theory other than Musicology. It is imperative to conduct music research under the iconology theory and method, since Music Iconography is a discipline which interrelates with musicology and Iconology. Yet, this is not an easy issue, since many kinds of symbols related to music are focused along with the expansion of Music Iconography research, which are involved in Semeiology, Religious Science, Philosophy, Aesthetics, and other disciplines. With the Music Iconography's inclusion into Higher Education Teaching System, colleges and universities such as Chinese National Academic of Arts and R \& D institutions take the first step to enroll and foster postgraduates in Music Iconography research. Hence, art and education, etc. are involved in Music Iconography research.

\section{Conclusion}

In general, the research and construction of Music Iconography are under a full swing, so we should adopt the academic path from two aspects: "horizontal logic" and "longitudinal logic". The contemporary research and construction of Music Iconography in our country are learned from abroad along with our traditional Music Iconography and historical course of reform and opening-up. As the logic premises of Music Iconography's research and construction as well as the successors' thinking quality and historical responsibility, it s required to follow the practice process to summarize the precursors' successful experience of exploring academic path and absorb the existing experience and theories overseas to maintain Music Iconography academic path's integrity. Those devoted to Music Iconography and the research and construction of Music Iconography should place Music Iconography theory abstracted from Music Iconography abroad in a proper position, and take it as a step to analyze, summarize, and complete the practice rather than instructing our Music Iconography practice or regarding it as a step or channel attached to existing theory to carry out our strategy. Therefore, those devoted to the research and construction of Music Iconography should avoid the academic position and direction by separating Music Iconography practice to deliberately pursue international standard and construct a general theory in the sense of "ontology".

\section{References}

GAO, Q. (1992). Music Iconography (translated from 1980 Edition of New Grove Dictionary of Music and Musicians). Chinese Musicology, 3, 138-144.

HAN, G. H. (1988). The scope and significance of Music Iconography. Chinese Musicology, 4, 54-55.

JIN, J. Y. (1989). Music Iconography and “pictures’ music history”. Chinese Musicology, 4, 39-42.

LI, R. Y. (2005). A study on developmental discipline of Music Iconography in education. Chinese Musicology, 4, 102-104, 88.

LI, R. Y. (2006). Musical Iconology: Its history, current situation, and a modest proposal for its future development. Journal of the Central Conservatory of Music, 1, 94-100, 135.

LUO, X. W. (2009). The Music Iconography study in China and some opinions. Journal of Yuxi Normal University, 7, 66-70.

LUO, Y. L. (2009). Consideration of Chinese Musical Iconography. Musicology in China, 1, 99-102.

MAO, T.-T. (1991). Selected works of Mao Tse-Tung (volume 1). Beijing: People’s Publishing House.

TIAN, D. C. (1990). Music Iconography. People’s Music, 1, 51-53.

WANG, L. (2005). [Night Revels of Han Xizai] in Western Music Iconographers' eyes. Ethnic Art Research, 5, 4-12.

ZI, W. J. (2007). Review on ideology and national interest. Contemporary World \& Socialism, 4, 150-155. 